\title{
NEWAVE VERSUS ODIN: COMPARISON OF STOCHASTIC AND DETERMINISTIC MODELS FOR THE LONG TERM HYDROPOWER SCHEDULING OF THE INTERCONNECTED BRAZILIAN SYSTEM
}

\author{
Mônica Zambelli* \\ monica@cose.fee.unicamp.br \\ Secundino Soares Filho* \\ dinodcose.fee.unicamp.br
}

\author{
André Emilio Toscano* \\ atoscano@cose.fee.unicamp.br
}

Erinaldo dos Santos ${ }^{\dagger}$

erinaldo@gmail.com

\author{
Donato da Silva Filho \\ donato.filho@edpbr.com.br \\ *UNICAMP \\ Campinas, SP, Brazil \\ ${ }^{\dagger} \mathrm{CESP}$ \\ São Paulo, SP, Brazil \\ $\ddagger$ EDP \\ São Paulo, SP, Brazil
}

\section{RESUMO}

NEWAVE Versus ODIN: Comparação entre Modelo Estocástico e Determinístico no Planejamento da Operação Energética do Sistema Interligado Nacional

Este artigo compara o modelo NEWAVE, uma abordagem baseada em programação dinâmica dual estocástica usada no Brasil para o planejamento da operação de médio prazo, com o modelo ODIN (Otimização de Despacho Interligado Nacional), uma abordagem determinística baseada em modelo de controle preditivo. A primeira adota uma representação agregada do sistema e aproximações lineares para possibilitar a aplicação da técnica de programação dinâmica ao sistema brasileiro. A última usa um algoritmo de otimização não linear considerando vazões futuras previstas com uma representação detalhada das usinas individualmente. Dados de fontes oficiais foram usados para formular um caso de estudo sobre o planejamento mensal de Janeiro de 2011 que

Artigo submetido em 10/03/2011 (Id.: 01298)

Revisado em 30/05/2011, 08/08/2011

Aceito sob recomendação do Editor Associado Prof. Carlos Roberto Minussi considera os planos de expansão até dezembro de 2015. Os testes foram realizados por simulação utilizando 75 séries históricos de vazões. Em comparação com o planejamento fornecido pela abordagem estocástica em vigor, a abordagem determinística proposta apresentou desempenho superior devido ao uso mais eficiente dos recursos hídricos, levando a uma operação mais segura e econômica.

PALAVRAS-CHAVE: Sistemas de potência, planejamento hydrotérmico, otimização não linear, otimização estocástica, operação de reservatório, modelo NEWAVE, modelo ODIN.

\section{ABSTRACT}

This paper compares the NEWAVE model, a stochastic dual dynamic programming based approach used in Brazil for the long term hydropower scheduling of the interconnected Brazilian power system, to the ODIN model (Optimal Dispatch for the Interconnected Brazilian National system), a deterministic approach based on model predictive control. The former adopts a composite representation of the hydro 
system and piecewise linear approximations to make the application of dynamic programming solution technique possible to the Brazilian system. The latter uses a nonlinear optimization algorithm considering predicted future inflows with a detailed representation of the individual power plants. Data from official sources were used to formulate a case study on the monthly operation planning of January 2011 that considers the projected expansion plans up to December 2015. Tests were performed by simulation using 75 historical inflow scenarios. In comparison to the scheduling provided by the stochastic approach, the proposed deterministic one was found to provide a superior performance due to the more efficient use of water resources, leading to a more secure and economic operation.

KEYWORDS: Power systems, long term hydrothermal scheduling, nonlinear optimization, stochastic optimization, reservoir operation, NEWAVE model, ODIN model.

\section{INTRODUCTION}

The hydropower scheduling is designed to meet the load demands of a power system using a reliable and cost effective power plant dispatching. This involves using the available hydropower resources optimally to reduce operating costs without compromising the security of system operation in the future.

Long term hydropower scheduling (LTHS) for a multireservoir system consists on a quite complex optimization problem due to issues such as the long planning horizon to be analyzed (several years), the time dependence of decisions, the coupling of hydro plants in the same river basin, and the nonlinear relations involved in the hydro power generation functions and thermal costs.

In Brazil the operation planning of the hydrothermal system is coordinated by the independent system operator (ONS) in accordance with the electric sector agents providing a coordinated dispatch for the whole system. The continental dimension of the country presents an extra challenge, since the system consists of a large number of thermal and hydro plants and an extensive transmission network linking the plants to the load centers.

Above all this, the major concern in hydrothermal scheduling is the stochastic nature of inflows. Various approaches have been proposed to solve the LTHS problem and they can all be classified as either stochastic or deterministic according to the modeling of inflows (Labadie, 2004).

Stochastic approaches usually consider the uncertainty of water inflows on the basis of probability distribution functions and most of the applications use stochastic dynamic programming (SDP) as optimization tool (Stedinger et.al., 1984). SDP has been the most commonly used technique in the solution of the strategic (long term) problem of reservoir operation. Among its advantages is the possibility to explicitly model the uncertainty of inflows and to represent important nonlinear relations inherent to the problem. However, for multireservoir systems, they require some kind of simplification due to the intense computational requirements (Bellman, 1957).

One way of overcoming this problem is by aggregating multiple reservoirs to form a composite reservoir of energy (Arvanitidis and Rosing, 1970; Turgeon, 1980; Valdes et.al., 1995), and/or by piecewise linear approximation of nonlinear functions (Diniz et.al., 2008; Dias et.al., 2010). This is the case of the methodology currently used in Brazil, the NEWAVE model, which is based on stochastic dual dynamic programming (SDDP) (Pereira and Pinto, 1991), using Benders decomposition (Pereira and Pinto, 1985) with nonlinearities in the power generation and future cost functions modeled as piecewise linear.

Deterministic approaches, on the other hand, take into consideration specific hydrological scenarios and provide solutions for individual plants. The stochastic aspects of the problem can thus be implicitly handled by the selection of such inflow scenarios and by the analysis of the optimal deterministic solutions associated with each one of them (Dembo, 1991; Escudero et.al., 1996). The advantage of this approach, also known as implicit stochastic optimization or Monte Carlo optimization, is that nonlinear models can be directly applied even to large scale hydropower systems. The primary disadvantage is that optimal operational policies are specific to the assumed hydrologic time series and deriving a general optimal operation rule is not straightforward.

Few articles have been published comparing the application of stochastic and deterministic approaches to the solution of LTHS problems (Zambelli et.al., 2006; Martinez and Soares, 2002; Philbrick and Kitanidis, 1999; Dagli and Miles, 1980; Boshier and Read, 1982). Case studies comprise only systems with a limited number of reservoirs (most of them, a single one) and general conclusions diverge, indicating that the best optimization approach is not yet defined by the literature.

This paper proposes the application of a new deterministic approach for the LTHS of the Brazilian National Interconnected System (SIN). The model named Optimal Dispatch for the Interconnected Brazilian National system (ODIN) is based on adaptive model predictive control (MPC), an optimization framework widely applied in real-time control and industrial processes which can provide high quality subopti- 
mal solutions for the LTHS problem with no computational burden.

The performance of the proposed approach is evaluated by simulation taking into account detailed plant data and all operational constraints from official data sources (CCEE). Simulations were performed for the 75 scenarios contained in the historical records of inflows.

Results from the ODIN model are compared to those provided by the stochastic approach given by the NEWAVE model using the SUISHI-O model to disaggregate the former's optimal rules and make the comparison possible on the basis of individual hydro plants. Both tools are used officially by the Brazilian Electric Sector (SEB) in the planning and operation of SIN.

This work is organized into four sections. Section 2 presents the problem formulation. Sections 3 and 4 describe, respectively, the proposed deterministic approach ODIN and the stochastic approach determined by official SEB models. Section 5 presents the case study and its results while Section 6 summarizes the main conclusions.

\section{PROBLEM FORMULATION}

The LTHS for large scale power systems is generally broken into separable sub-problems to make a solution possible. The primary goal is to supply the total load demand $D_{t}$ at minimum expected operating costs, which leads to the hydro scheduling optimization problem that follows:

$$
\min _{q} \varepsilon_{y} \sum_{t=1}^{T}\left\{\lambda_{t} . \Psi\left(D_{t}-p_{t}\right)\right\}
$$

Subject to:

$$
\begin{gathered}
p_{t}=\sum_{i=1}^{I} p_{i, t}+P_{C t} \\
p_{i, t}=k_{i} \cdot h_{i, t} \cdot q_{i, t} \\
h_{i, t}=h_{M i}\left(x_{i, t}^{a v g}\right)-h_{J i}\left(u_{i, t}\right)-h_{P i}\left(q_{i, t}\right) \\
x_{i, t}^{a v g}=\frac{x_{i, t-1}+x_{i, t}}{2}
\end{gathered}
$$

$$
\begin{gathered}
x_{i, t}=x_{i, t-1}+\left(y_{i, t}+\sum_{k \in \Omega_{i}} u_{k, t}-u_{i, t}-e v-U_{C}\right) \cdot \gamma_{t} \\
u_{i, t}=q_{i, t}+v_{i, t} \\
X_{i, t}^{\min } \leq x_{i, t} \leq X_{i, t}^{\max } \\
u_{i, t} \geq U_{i, t}^{\min } \\
q_{i, t} \leq q_{i, t}^{\max }\left(h_{i, t}\right) \\
v_{i, t} \geq 0
\end{gathered}
$$

where:

$t:$ time stage index (months);

$T:$ number of time stages in planning period;

$I$ : number of hydro plants;

$(i, t)$ : plant i during stage $\mathrm{t} ;$

$\lambda_{t}:$ discount rate for stage $\mathrm{t}$;

$p:$ power generation $[M W]$;

$P_{C t}$ : hydropower from small generators $[M W]$;

$D:$ load demand $[M W]$;

$k:$ constant efficiency factor $[M W / m 3 / s / m]$;

$h:$ water head $[m]$

$h_{M}$ : forebay elevation function $[m]$;

$h_{J}:$ tailrace elevation function $[m]$;

$h_{P}$ : penstock head loss function $[m]$;

$x:$ reservoir storage at end of current stage $\left[\mathrm{hm}^{3}\right]$;

$x^{a v g}:$ average reservoir storage $\left[\mathrm{hm}^{3}\right]$;

$X^{\min }, X^{\max }$ :bounds on reservoir operation $\left[\mathrm{hm}^{3}\right]$;

$u$ :water release from reservoir $\left[\mathrm{m}^{3} / \mathrm{s}\right]$;

$q$ :water discharge through turbines $\left[\mathrm{m}^{3} / \mathrm{s}\right]$; 
$v$ :water spill from reservoir $\left[\mathrm{m}^{3} / \mathrm{s}\right]$;

$y$ :incremental water inflow $\left[\mathrm{m}^{3} / \mathrm{s}\right]$;

$e v$ :water evaporated from reservoir $\left[\mathrm{m}^{3} / \mathrm{s}\right]$;

$U_{C}$ :water taken for alternative uses $\left[\mathrm{m}^{3} / \mathrm{s}\right]$

$\gamma$ :factor for conversion of flow from $\mathrm{m}^{3} / \mathrm{s}$ to $\mathrm{hm}^{3} /$ month;

$\Omega_{i}$ :set of plants located immediately above hydro plant $\mathrm{i}$ in the same river basin.

The cost function $\Psi($.$) represents generation fuel costs as-$ sociated to non-hydraulic sources dispatched supplementary to attend the load demand. Costs associated with hydroelectric power generation are considered to be negligible in relation to those of thermal generation and were thus ignored in this model. The coefficient $\lambda_{t}$ represents the interest rate adopted to calculate the present value of the operating costs on a monthly basis.

Hydro power generation at stage $t$ is calculated in (2) as the sum of the power generation of each individual plant plus that of small generators (less than $30 \mathrm{MW}$ ) from hydro and alternative sources $P_{C t}$, which are not explicitly controlled by the ONS. For each individual plant, the hydro power generation $p_{i}$ is a nonlinear function of the water head and the discharge (3) .

Water head (4), in turn, is a nonlinear function of average reservoir storage, water discharge through the turbines, and water spillage from the reservoir. The constant $k$ represents the product of the water density, the gravity acceleration, and average turbine/generator efficiency. The forebay $h_{M}(x)$ and tailrace $h_{J}(u)$ elevations are calculated by 4 th degree polynomial functions and the penstock head loss $h_{P}(q)$ is determined by a quadratic function of discharge, a constant, or a percentage of the water head, depending on the data available for the plant.

The equality constraint (6) describes the system dynamics based on the water balance in the reservoir. Amounts of water taken from the reservoir for alternative purposes are included in term $U_{C}$. Evaporation $e v$ is a nonlinear function of the reservoir storage and despite being properly calculated in simulation time, it was not considered during optimization in order to preserve the linearity of constraint (6).

Lower and upper bounds on variables, expressed by constraints (8) -(11), are imposed by the physical operational limits of the hydro plants, as well as the limitations associated with multiple uses of water. For example, the lower bound for reservoir and release can vary over time to allow navigation, water supply, irrigation and recreation. The upper bound for reservoir can be imposed for purpose of dam safety and flood control. The upper limit of the discharge in equation (10) is also a nonlinear function of water head.

Since spillage $v$ does not produce energy, and therefore does not reduce thermal generation costs, it is considered a slack variable, which will only be different from zero if the release is greater than the maximum possible discharge $\left(u>q^{\max }\right)$ so the reservoir cannot accommodate any more water $\left(x=X^{\max }\right)$.

The total thermal generation $z_{t}$ to be produced at a given stage $t$, can be calculated as the total power needed, supplementary to total hydro generation $p_{t}$, to guarantee the full supply of load demand $D_{t}$.

$$
z_{t}=D_{t}-p_{t}
$$

Substituting (12) in (1) and specifying $\Psi($.$) as the product of$ thermal unit generation for its variable costs, a thermal optimization problem is formulated to determine the economic dispatch of individual thermal units (El-Hawary and Christensen, 1979) as presented in equations (13) -(15)

$$
\begin{gathered}
\Psi\left(z_{t}\right)=\min \sum_{j=1}^{J} C_{j, t} \cdot z_{j, t} \\
z_{t}=\sum_{j=1}^{J} z_{j, t} \\
Z_{j, t}^{\min } \leq z_{j, t} \leq Z_{j, t}^{\max }
\end{gathered}
$$

where:

$J$ :number of thermal plants;

$C$ :thermal unit generation cost $[R \$ / M W]$;

$z$ :thermal generation $[M W]$;

$Z^{\min }, Z^{\max }$ :bounds on thermal generation $[M W]$;

The coefficients $C_{j, t}$ are variable unitary costs for each thermal plant $j$ and stage $t$. Costs related to importing electricity from neighboring markets and energy deficits can be modeled in a similar way.

In equation (15) the minimum limit for thermal generation at a stage $t$ is defined by operational limits or imposed by contracts for the fuel supply (thermal inflexibility), if any. The upper limit is determined by the generation capacity of 
the plant, which is the installed capacity discounting maintenance and unexpected outage factors.

According to the current SIN model the hydro plants are aggregated in four subsystems that correspond to distinct geographic areas of Brazil. The main interconnections between these subsystems are explicitly considered in the model, so that energy balance within each subsystem $s$ is assured and implicit active power flow $o_{s, t}$ in the main network is calculated by equations (16) -(20) .

$$
\begin{gathered}
o_{s, t}+p_{s, t}+z_{s, t}=D_{s, t} \\
z_{s, t}=\sum_{\forall j \in s} z_{j, t} \\
p_{s, t}=\sum_{\forall i \in s} p_{i, t}+\sum_{\forall k \in s} P_{C k, t} \\
o_{s, t}=\sum_{n \in \mathrm{N}_{s}} o_{(n, s), t} \\
-O_{(s, n), t}^{\max } \leq o_{(n, s), t} \leq O_{(n, s), t}^{\max }
\end{gathered}
$$

where

$(s, t)$ :subsystem $s$ during stage $t$;

$o$ :power flow on a connection $[M W]$;

$N_{s}$ :set of subsystems connected to $s$;

$(n, s)$ :connection between two subsystems $n$ and $s$;

$O^{\max }$ :active power flow capacity of a connection $[M W]$;

Equations (16), (17) and (18) are analogous to (12), (14) and (2) respectively but in this context power generation is summarized for each subsystem.

\section{THE DETERMINISTIC APPROACH}

The deterministic operating policy ODIN proposed here is an open-loop approach where strategic decisions are not calculated prior to the simulation process for all stages of the planning horizon, but rather determined at each stage during the simulation. It is an operating policy based on MPC where decisions are determined, at each stage of the planning period, by a two step procedure: in the first step the future inflows are forecasted for a limited time horizon. Then, in a second step the system is optimized for the forecasted inflows by a nonlinear deterministic optimization model.

The simulation of the system's operation with such an open-loop approach results on a "forecast-optimize-update" scheme that runs for all stages until the end of the planning horizon.

Previous tests with this approach, focusing specifically on the uncertainty of inflows, evaluated the results for single reservoir systems where dimension is not an issue (Martinez and Soares, 2002; Zambelli et.al. 2009). The approach has shown results equivalent to those of standard methods based on stochastic dynamic programming.

Figure 1 presents a diagram for the predictive control operating policy at a certain stage $t$.

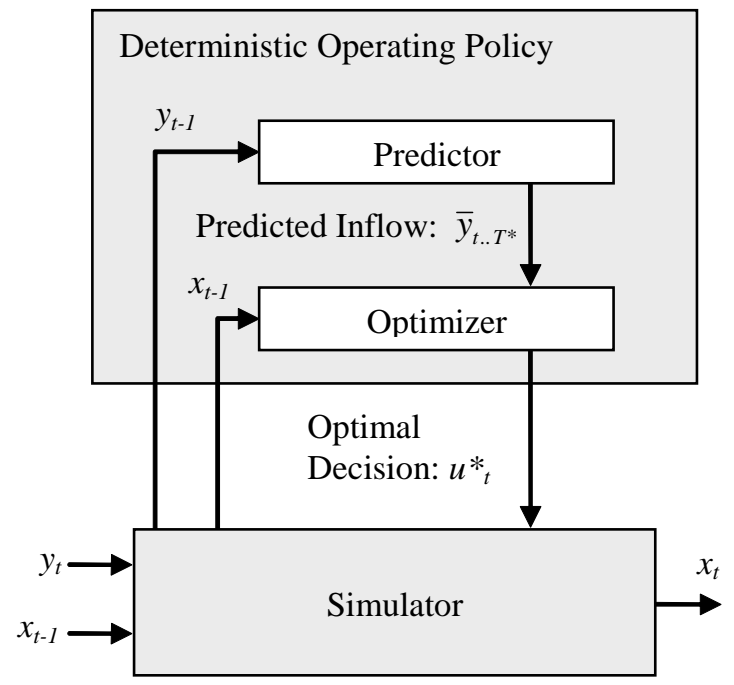

Figure 1: Predictive control scheme.

During the simulation, for each stage $t$ of the planning horizon, the reservoir storage level at the end of the previous stage is observed and used as an initial condition for solving a deterministic optimization problem for a specific optimization horizon $\left[t, T^{*}\right]$.

This optimization considers a series of predicted values for the unknown parameters to be considered, in this case, water inflows, determined by the Predictor module, based on past observed values.

The Optimizer module then provides optimal releases for each hydro plant for the optimization horizon but only the discharge solution for the first stage $u *_{t}$ is selected and submitted to a simulation model. The latter tests the feasibility of results and makes the necessary corrections if needed, according to formulation (2) -(20) . Corrections are frequently 
needed due to differences between the predicted inflow series $\bar{y}$ and the simulated inflow series $y$ and eventually due to subsystems' interchange constraints.

In the next stage $t+1$, the storage level of the reservoirs resulting from simulation is observed, and a new forecasting of inflows can be given based on the latest available information. This procedure of "forecast-optimize-update" is repeated until the end of the planning horizon $T$.

In this paper the monthly average of historical inflow records (MLT) was adopted as the forecasting values for the inflow series during optimization, which neglects the benefits of the updating scheme. This means that the performance of the approach implemented can probably be improved significantly with the use of more efficient forecasting techniques.

In the ODIN approach the deterministic nonlinear optimization model (1) -(11) can be solved using specialized optimization techniques to such as network flow algorithms with capacitated arcs (Oliveira and Soares, 1995) or interior point methods (Azevedo, et. al. 2009). The former was used in this case study since it is much more efficient than conventional nonlinear programming models for solving hydro scheduling problems (Rosenthal, 1981). Its structure allows a detailed representation of the hydropower system, including specific aspects of individual plants and nonlinear production functions.

The optimization horizon $T^{*}$ adopted starts at the current stage $t$ and consists on a rolling window of at least 13 months and at most 24 months, depending on the current monthly stage. Full reservoir storage is imposed as a boundary condition at the end of this horizon, adjusted to match the month of April, since reservoirs are expected to be close to full by the end of the wet seasons. These two parameters were estimated based on successive simulation tests with various considerations and have shown to maximize the approach performance.

Since the optimization algorithm used by ODIN is based on a network flow algorithm, it can not consider limits on interchange between subsystems. Therefore, heuristic operating rules can be applied to the optimal solution during simulation in order to enforce the limits of transmission capacity between subsystems and verify the supply of local load demands, according to Eq. (16) -(20) (Zambelli, 2009).

\section{THE STOCHASTIC APPROACH}

The stochastic operating policy adopted by the ONS in Brazil is a closed-loop approach performed in two steps: first the optimal strategy is calculated by an optimization model and then the system is simulated using this strategy over different hydrological scenarios in order to evaluate its performance.

The first step is done by the NEWAVE model (CEPEL, 2001) and is based on SDDP, a technique derived from the standard stochastic dynamic programming by the hypothesis that the inflows at the beginning of each stage are known. With this hypothesis, the classical "decision-hazard" Belman's recursive equation can be substituted by a "hazard-decision" recursion which can be solved through a nested resolution of two stage problems during the planning period using Benders decomposition. These two stage problems optimize the immediate present operation cost during the actual stage plus the minimum expected future operation costs at the end of that stage.

According to this approach, the minimum expected future cost function (FCF) at each stage, which indeed is a nonlinear function of storage, is approximated by its external linearization (Benders cuts). The construction of such an approximation is performed by an iterative procedure constituted by forward and backward simulations over synthetic inflows generated by periodic autoregressive models of order $\mathrm{p}, \operatorname{PAR}(\mathrm{p})$, until convergence is achieved which results in a piecewise linear FCF.

The NEWAVE model, developed by the Electric Energy Research Center (CEPEL) is the first in the chain of models (Maceira et.al., 2002) used to guide the planning and operation of the Brazilian power system. It uses the SDDP technique to determine an optimal operation for the SIN represented as four interconnected subsystems: North $(\mathrm{N})$, Northeast (NE), Southeast and Center-West (SE/CO), and South(S). Each of these is associated to a single composite energy reservoir, a thermal system, a load demand and limited energy interchange capacity. The composite representation was necessary since SDDP application to large scale problems is very CPU-time consuming.

The outcomes from the NEWAVE model are the FCF functions for each subsystem and each stage of the planning horizon which will be used next.

The second step in the closed-loop approach is the simulation of the system using the strategy (FCF) calculated by NEWAVE in the previous step. In this paper, the simulation was performed by the SUISHI-O model (CEPEL, 2007), also developed by CEPEL, that disaggregates the dispatch for the individual plants based on the FCF functions provided by NEWAVE.

This disaggregation is accomplished for each stage also in two steps: in the first step a linear programming model optimizes the hydrothermal dispatch of the subsystems taking into account the FCF functions (Benders cuts) provided 
by the NEWAVE model and the interchange capacity limits. In the second step, the hydro generation of each subsystem is disaggregated into its individual hydro plants by using heuristic reservoir operation rules that try to maintain the reservoirs at the same storage levels (parallel operation). Although using a heuristic approach, the SUISHI-O model computes the precise consequences of the decisions since its formulation represents the nonlinear aspects of hydro production.

In summary, this approach, which will be referred to as NWSUISHI, has the following modeling simplifications:

1. Composite representation of hydro subsystems;

2. Inflow knowledge at the beginning of each stage;

3. Recursive equation of "hazard-decision" type;

4. Piecewise linear approximation of hydro production and future cost functions;

5. Heuristic reservoir operation rules.

\section{CASE STUDY}

The performance of the two approaches was analyzed using simulation in a support decision system developed at UNICAMP. A data importation module was created so that the system could contemplate all the operating data available in official sources (www.ccee.org.br). For this paper work the January 2011 data deck (NW201101) was imported to create a case study which takes into consideration the dynamic evolution of the power plants and load demand projections up to December 2015.

The hydrothermal planning performed in Brazil considers a time horizon of up to five years on a monthly basis, thus the simulation studies involved the 75 inflows scenarios contained in the historical data from 1931 to 2009, starting in January of each year and comprising 60 monthly periods.

\subsection{Systems Results}

In Table 1, the simulation results for the stochastic (NWSUISHI) and deterministic (ODIN) approaches are summarized. Average values of hydropower generation, stored energy associated with reservoir storage at the end of the planning period, and operating costs updated to present values according to a discount rate of $12 \%$ per year, are presented.

The average results indicate that the deterministic approach provided $8.23 \%$ lower operating costs, with $0.81 \%$ greater hydropower generation, and almost $38.9 \%$ more stored energy by the end of 2015 .
Table 1: General Statistical Simulation Results

\begin{tabular}{c|r|r|r}
\hline & \multicolumn{1}{|l|}{$\begin{array}{l}\text { Operating } \\
\text { Cost* } \\
\text { (Million } \\
\text { US\$) }\end{array}$} & $\begin{array}{l}\text { Hydropower } \\
\text { Generation } \\
\text { (MWmonth) }\end{array}$ & $\begin{array}{l}\text { Final } \\
\text { Stored En- } \\
\text { ergy(MWmonth) }\end{array}$ \\
\hline NW-SUISHI & 18820 & 50763 & 102867 \\
\hline ODIN & 17270 & 51174 & 142879 \\
\hline
\end{tabular}

$*$ Currency conversion on 22/02/2011: 1 US $\$=1,67 \mathrm{R} \$$

These results are a consequence of the more efficient operation of hydro plants resulting from deterministic modeling, which frequently operate with greater reservoir storage. The greater efficiency helps meeting load demands using less water from the reservoirs, which also provides a more reliable operation.

Figures 2 and 3 present the evolution of average hydropower generation and operating costs, respectively, for the simulated models.

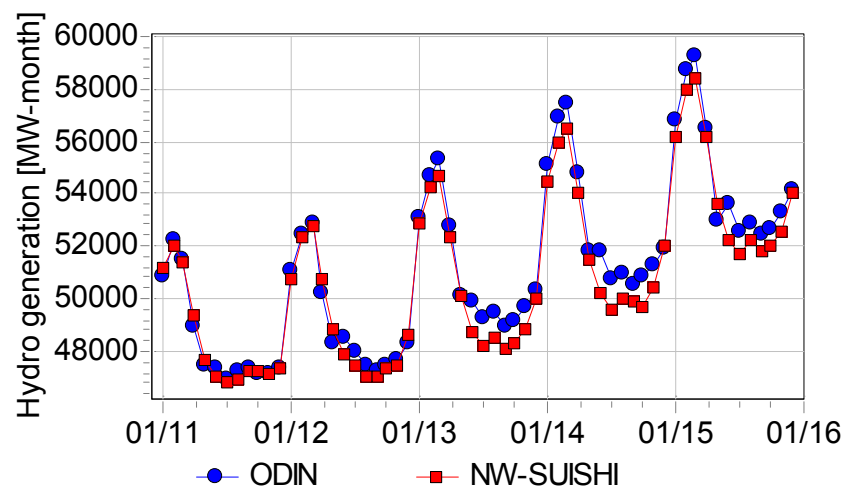

Figure 2: SIN average hydropower generation.

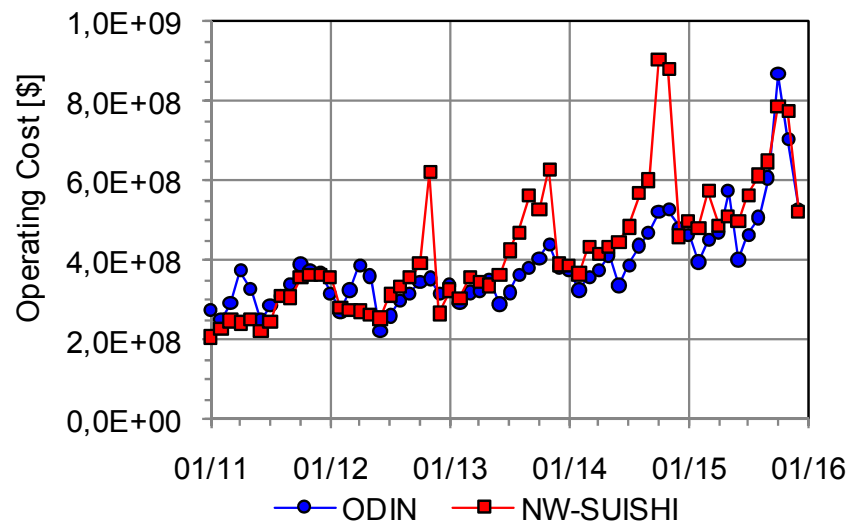

Figure 3: SIN average operating costs.

Figure 2 shows that both policies follow the same seasonal pattern of hydropower generation, following the fluctuation 
of inflows throughout the year, with peaks of generation in the month of March. Although the two models present similar hydro generation values for the first two years (with greater power generation of the NW-SUISHI model in the wet months near the peaks), for the following three years of the planning horizon, especially in the dry season, the ODIN model provides significantly greater hydro generation due to the better management of reservoir storage during the annual emptying and filling of the reservoirs in cascade.

During dry periods, when the water supply is reduced, SIN incurs on higher operational costs, as seen in the trajectory of operating costs shown in Figure 3. The graph of operating costs presents peaks in October for the NW-SUISHI model, while the ODIN model anticipates the use of thermal generation to avoid these peaks and reduce costs over almost the entire planning period.

To provide a better view of each scenario, the graph in Figure 4 presents the difference in costs (NW-SUISHI minus ODIN) for each scenario. Differences in final reservoir storage were uniformly distributed over the five-year period, multiplied by average marginal costs and added to original operating costs to state a single base of comparison.

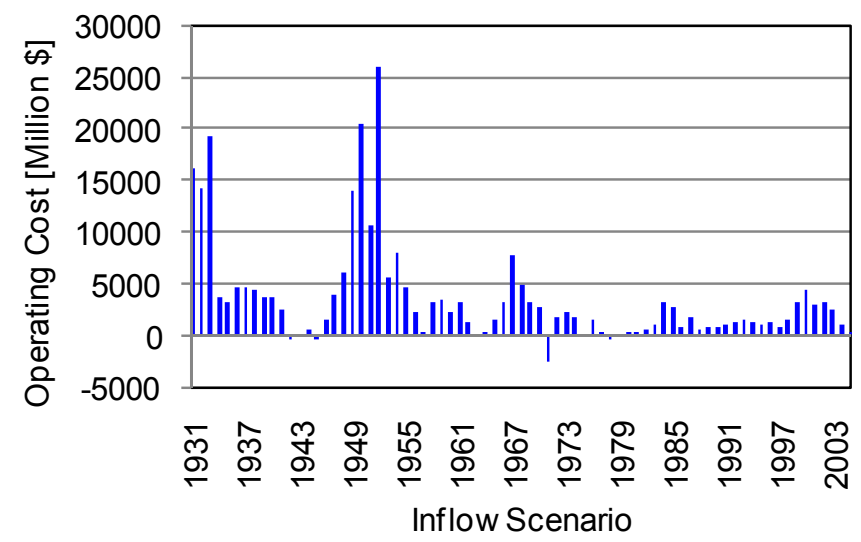

Figure 4: ODIN minus NW-SUISHI operating costs for each inflow scenario.

As can be observed in Figure 4, the ODIN model provided a more economic operation for the vast majority of the scenarios studied. Indeed the results were significantly improved by the NW-SUISHI model only in one of the 75 hydrologic scenarios simulated.

Figure 5 presents the trajectory of average stored energy resulting from simulation with the two models.

It is shown that the ODIN model tries to maintain a greater stock of stored energy throughout the planning period in order to increase efficiency in operation of the hydro plants. It

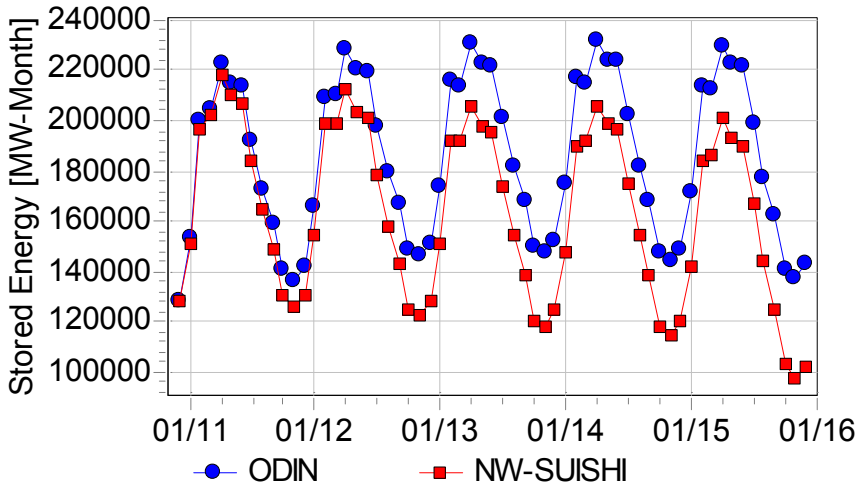

Figure 5: SIN average stored energy.

also shows that operating according to the ODIN model the system makes it possible to recover maximum energy storage at the end of each dry season in April, whereas operating with the NW-SUISHI model gradually reduces the stored energy supply each year.

This difference is of special importance to the case study conducted. Apparently, the solution of the NW-SUISHI model does not provide a steady state operation, and leading to a continuous depletion of the reservoirs, which suggests that this operating policy is not sustainable in the long run. This characteristic may be a consequence of the simplifications adopted, specially the linearization of nonlinear functions, the "hazard-decision" recursive equation of SDDP, and the heuristic rule of reservoir parallel operation of SUISHI-O model.

It is also possible to say that operation according to the NWSUISHI model is less reliable than that proposed by the ODIN model, since the former makes use of the water stored in the system beyond what is sustainable in the long run, exposing the system to greater risk of rationing.

Perhaps this fact explains why it was necessary for the ONS to introduce a Risk Aversion Curve (CAR) in the SIN monthly operation program, once noticed that the model could lead to expressive depletion. One major advantage of the ODIN model is that it requires no CAR or any other extramodel procedures to ensure safe operation and avoid deep shortages that would have deep economic impact.

\subsection{Subsystems Results}

In this Section results are presented for the four subsystems that compose the SIN according to geographic regions. These are Southeast/Central-west (SE/CO), South (S), Northeast (NE) and North (N). 
Tables 2 and 3 show, respectively, the mean and standard deviation values of the marginal operating costs for each subsystem, concerning the whole planning period and the 75 simulated scenarios. The expected value of marginal operating costs is used as indicative price of energy in the Brazilian spot market.

Table 2: Expected Values of Marginal Operating Costs for Subsystems

\begin{tabular}{l|l|l|l|l}
\hline & $\begin{array}{l}\text { SE/CO } \\
(\$ / M W h)\end{array}$ & $\begin{array}{l}\text { S } \\
(\$ / M W h)\end{array}$ & $\begin{array}{l}\text { NE } \\
(\$ / M W h)\end{array}$ & $\begin{array}{l}\mathrm{N} \\
(\$ / M W h)\end{array}$ \\
\hline NW-SUISHI & 104,94 & 102,09 & 67,15 & 89,77 \\
\hline ODIN & 82,54 & 82,65 & 80,44 & 81,76 \\
\hline
\end{tabular}

Table 3: Standard Deviations of Marginal Operating Costs for Subsystems

\begin{tabular}{l|l|l|l|l}
\hline & $\begin{array}{l}\text { SE/CO } \\
(\$ / M W h)\end{array}$ & $\begin{array}{l}\text { S } \\
(\$ / M W h)\end{array}$ & $\begin{array}{l}\text { NE } \\
(\$ / M W h)\end{array}$ & $\begin{array}{l}\mathrm{N} \\
(\$ / M W h)\end{array}$ \\
\hline NW-SUISHI & 43,52 & 40,12 & 14,12 & 40,86 \\
\hline ODIN & 23,62 & 23,68 & 21,24 & 23,68 \\
\hline
\end{tabular}

It is shown that the deterministic methodology provides lower average marginal costs for all subsystems, as well as lower standard deviations, indicating that there is less price volatility using this methodology. Moreover, the differences between subsystems are much lower indicating that the limits on interchange were riched less frequently.

Figure 6 shows the average trajectories of the marginal operating costs according to the two approaches for the SE/CO subsystem, which is the largest one, corresponding to $61 \%$ of the hydro installed capacity of the SIN as a whole.

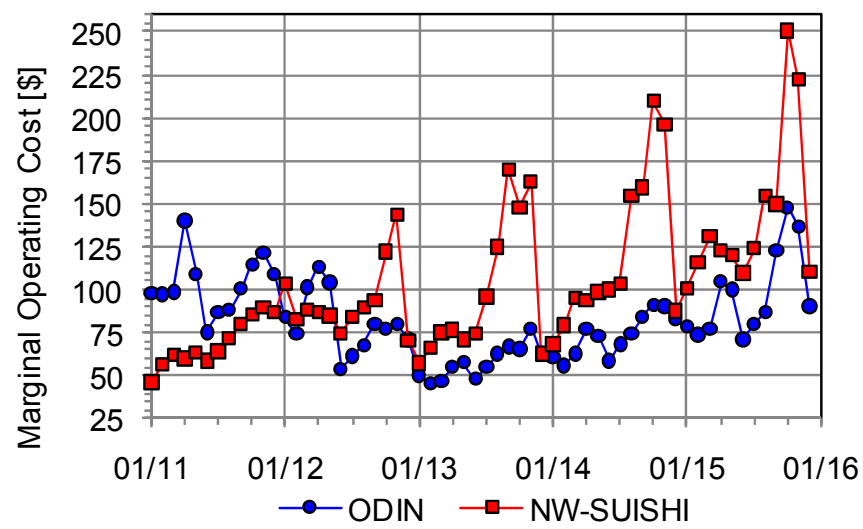

Figure 6: Marginal Operating Costs for SE/CO subsystem.

It can be observed that the NW-SUISHI model reports lower marginal costs along the whole first year but it fails to maintain this advantage for the entire planning period, incurring in higher prices especially during the dry seasons (May to November).

These results are directly related to the management of the reservoirs, as shown in Figure 5. The strategy of the ODIN model is to hold more water in the reservoirs at the beginning of the planning horizon in order to increase the system's storage and be able to operate it with more efficiency in the remaining planning period. This increases the operation costs at the first year, but assures lower and more stable prices along the whole planning horizon.

\subsection{Hydro Plants Results}

Four hydro plants, located in different river basins, were selected to illustrate the simulation results for individual plants. These are Emborcação (A), Foz do Areia (B), Sobradinho (C) and Serra da Mesa (D).

Figures 7 to 10 show the average evolution of storage in the reservoirs for these hydro plants, resultant from the scenario simulation using the two approaches considered. The maximum limit for storage $x$ Max is also presented.

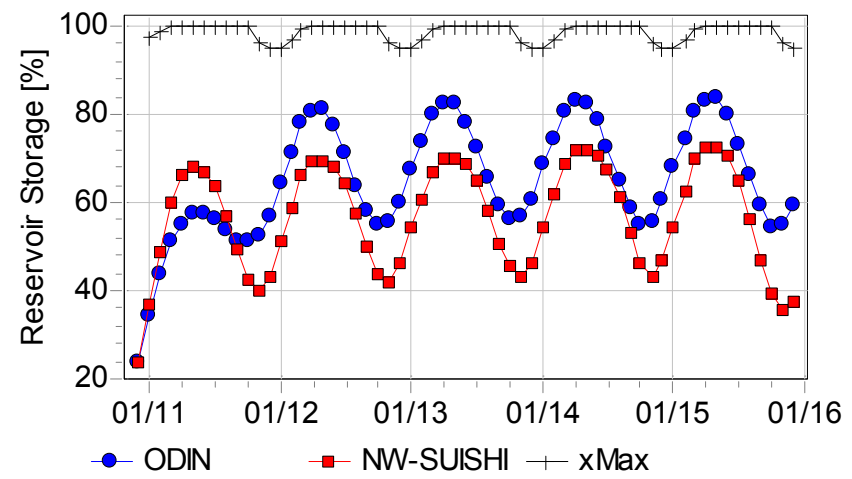

Figure 7: Average Reservoir Storage for Emborcação Plant (A).

It can be observed that the operation according to the ODIN model leaves the reservoirs with greater water storage than does the NW-SUISHI model. A similar pattern has been observed for most of the reservoirs in the SIN, which explains the results in Figure 5.

Indeed there is a strategic difference between the models concerning reservoir management: the ODIN model always tries to increase the level of water stored in the reservoirs, especially those whose inflows are greater (downstream plants). This is a result of the influence of water head on hydro efficiency and is only possible to be captured by nonlinear models (eq.(3) -(4) ). 


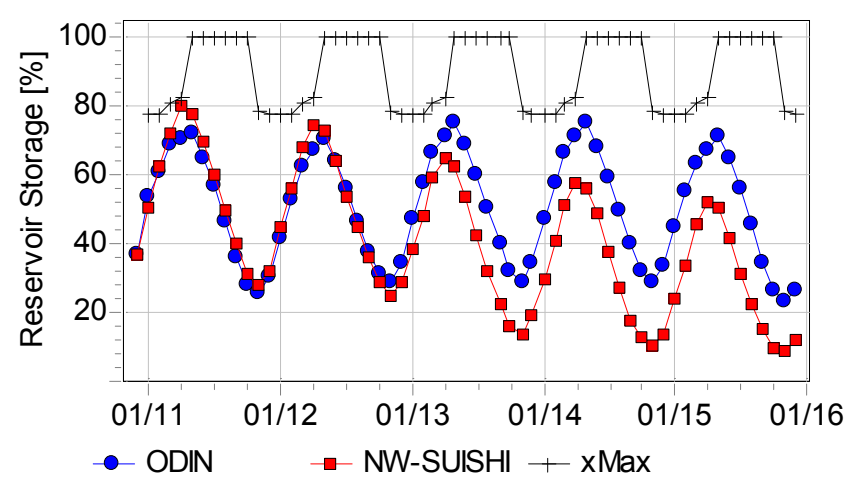

Figure 8: Average Reservoir Storage for Sobradinho Plant (B).

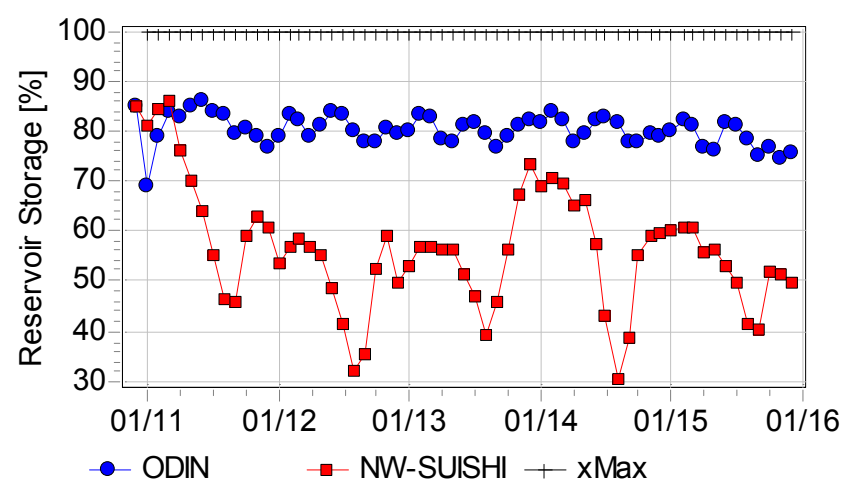

Figure 9: Average Reservoir Storage for Foz do Areia Plant (C).

Considering the individual hydro plants presented, this trend is easily observed for plants A and B. Plant C presents two quite different profiles according to both approaches but it is clear that the use of the ODIN approach provided more stable reservoir operation in response to the seasonable inflow profile for the region. Plant D shows no apparent difference in reservoir evolution with the two approaches. The differences noted are strongly related to characteristics of individual plants and their location in the river basins. Plant $\mathrm{C}$ is the one among these four with the smallest storage capacity $\left(3805 \mathrm{hm}^{3}\right)$, whereas plant D has the largest reservoir on SIN $\left(43250 \mathrm{hm}^{3}\right)$, indicating that perhaps the NW-SUISHI$\mathrm{O}$ approach, based on a piecewise linear production function, would lead to a more instable behavior in small storage plants.

Tables 4 and 5 present the average values for hydro generation, efficiency and reservoir storage at the end of the planning horizon for each plant, according to the stochastic and deterministic approaches, respectively.

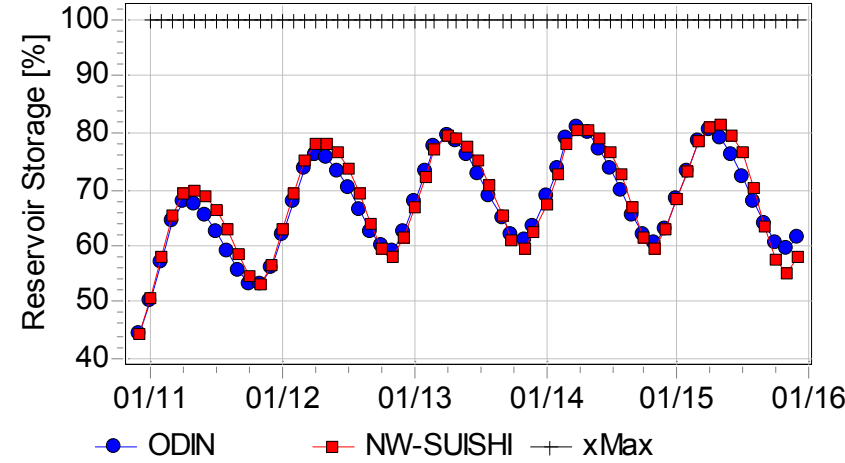

Figure 10: Average Reservoir Storage for Serra da Mesa Plant (D).

Table 4: Results for hydro plants determined by NEWAVE/SUISHI-O model

\begin{tabular}{c|c|c|c}
\hline & $\begin{array}{l}\text { Generation } \\
(\mathrm{MW} / \mathrm{month})\end{array}$ & $\begin{array}{l}\text { Efficiency } \\
\left(\mathrm{MW} / \mathrm{m}^{3} / \mathrm{s}\right)\end{array}$ & $\begin{array}{l}\text { Final Stored } \\
\text { Energy } \\
\text { (MWmonth) }\end{array}$ \\
\hline A & 461,6 & 1,070 & 37,6 \\
\hline B & 664,5 & 1,075 & 49,7 \\
\hline C & 508,6 & 0,209 & 12,0 \\
\hline D & 644,3 & 1,034 & 58,0
\end{tabular}

It can be observed that differences in the power generation diverge from one hydro plant to the other, with the stochastic model providing greater average generation for plants $A$ and $\mathrm{B}$, and the deterministic model doing so for plants $\mathrm{C}$ and D.

Average reservoir storages at the end of the planning period, however, were greater with the ODIN model for the four hydro plants. The greatest increase was observed for plant $\mathrm{C}$, with final reservoir level being more than double of that determined by the NW-SUISHI model.

The benefits of greater storage in reservoirs go beyond a mere hedge against droughts; the increase in water head also results in greater efficiency for the plant. Indeed, for all the hydro plants presented in Tables 4 and 5, the ODIN model has shown greater efficiency, with the greatest increase in re-

Table 5: Results for hydro plants determined by ODIN model

\begin{tabular}{c|c|c|c}
\hline & $\begin{array}{l}\text { Generation } \\
(\mathrm{MW} / \mathrm{month})\end{array}$ & $\begin{array}{l}\text { Efficiency } \\
\left(\mathrm{MW} / \mathrm{m}^{3} / \mathrm{s}\right)\end{array}$ & $\begin{array}{l}\text { Final Stored } \\
\text { Energy } \\
(\mathrm{MWmonth})\end{array}$ \\
\hline A & 460,5 & 1,108 & 59,1 \\
\hline B & 505,6 & 1,155 & 75,8 \\
\hline C & 687,1 & 0,221 & 26,2 \\
\hline D & 675,7 & 1,034 & 61,7
\end{tabular}


lation to that of the NW-SUISHI model being observed for plant B $(7.44 \%)$.

These results have shown that the deterministic approach provides better performance than the stochastic method for the long term hydrothermal scheduling of the multi-reservoir Brazilian power system. Moreover, for this case study, it led to an even more efficient operation of reservoirs which can be supported by the Certainty Equivalent principle (Bryson and Ho, 1975) (Tse and Shalom, 1975) that is believed to be true for reservoir operation problems when the performance criterion is the maximization of hydroelectric power generation (Philbrick and Kitanidis, 1999).

\section{CONCLUSIONS}

This paper has presented a comparison of stochastic and deterministic approaches for the long term hydrothermal scheduling of the Brazilian Power System.

The stochastic solution was represented by the stochastic dual dynamic programming approach used by the NEWAVE model in conjunction with the linear programming and heuristic rules used by the SUISHI-O model to disaggregate the former's results for individual plants.

The deterministic solution was represented by the predictive control model framework used by the ODIN, where optimal operational decisions for individual hydro plant are provided by a nonlinear optimization model based on expected values for the future inflows.

The two approaches have been evaluated by simulation over the 75 inflow scenarios contained in historical records for a case study that considers the interconnected Brazilian hydrothermal system with official data from the monthly operation program of January 2011.

The expected operating costs based on the deterministic model were $8.23 \%$ smaller than those established by the stochastic model. This was a consequence of the better management of the reservoirs of the system according to ODIN model, which made it possible to increase hydro power generation by $0.81 \%$ and still leave the system with almost $38.9 \%$ more stored energy by the end of the 60 -month planning period.

In general, the deterministic ODIN model can present a more efficient operation, resulting in greater hydropower generation and reduced costs. The ODIN model can also guarantee a safer and more reliable operation, as it maintains the reservoirs fuller while providing a more efficient use of the water resources.
Future work includes testing the performance of the ODIN model when using specialized inflow prediction models based on artificial intelligence techniques.

\section{ACKNOWLEDGEMENTS}

A preliminary version of this paper was presented at the Brazilian Automation Congress (CBA) in October 2010 (Zambelli et.al., 2010). The continuation of the research expressed in this paper, however, has been financed by the $\mathrm{Na}$ tional Regulatory Agency (ANEEL) strategic research and development project PE-0391-0108/2009 conducted by the EDP Group in association with several other generation and distribution companies.

\section{REFERENCES}

Arvanitidis, N.V. and Rosing, J. (1970). Composite Representation of a Multireservoir Hydroelectric Power System. IEEE Transactions on Power Apparatus and Systems. PAS-89 (2), pp. 319-326.

Azevedo, A.T., Oliveira, A.R.L. and Soares, S. (2009). Interior point method for long-term generation scheduling of large-scale hydrothermal systems. Annals of Operations Research, pp. 55-80.

Bellman, R.E. (1957). Dynamic Programming. Princeton University Press, Princeton, NJ.

Boshier, J.F. and Read, E.G. (1982). Stochastic Single Reservoir Models for Long-Term Scheduling of Hydrothermal Power Systems. Planning Division Internal Report, New Zealand Ministry of Energy, Reprinted in University of Tennessee.

Bryson, A.E., Jr., and Ho, Y. C. (1975). Applied optimal control. Washington, DC: Hemisphere Publishing Corp.

CEPEL, (2001). Manual de Referência-Modelo NEWAVE. Relatório Técnico, CEPEL, Rio de Janeiro, RJ.

CEPEL, (2007). Manual de Referência do Programa SUISHI-O 6.10 - Modelo de Simulação à Usinas Individualizadas para Subsistemas Hidrotérmicos Interligados. Relatório Técnico DP/DEA 51566/07 e 51572/07, CEPEL, Rio de Janeiro, RJ.

Dagli, C. H. and Miles, J.F. (1980). Determining Operating Policies for a Water Resources System, Journal of Hydrology, Vol.47, pp. 297-306.

Dembo, R.S. (1991). Scenario optimization. Annals of Operations Research. Vol. 30, No. 1, pp.63-80. 
Dias, B. H., Marcato, A. L. M., Souza, R. C., Soares, M.P., Silva Jr., I.C., Oliveira, E.J., Brandi, R.B.S. and Ramos, T.P. (2010) Stochastic Dynamic Programming Applied to Hydrothermal Power Systems Operation Planning Based on the Convex Hull Algorithm. Mathematical Problems in Engineering, vol. 2010, doi:10.1155/2010/390940

Diniz, A.L., Costa, F. S., Pimentel, A. L. G., Xavier, L. N. R. and Maceira, M. E. P. (2008) Improvement in the Hydro Plants Production Function for the Mid-Term Operation Planning Model in Hydrothermal Systems. International Conference on Engineering Optimization EngOpt 2008, Rio de Janeiro, Brazil.

El-Hawary, M. E. and Christensen, G. S. (1979). Optimal Economic Operation of Electric Power System. Academic Press.

Escudero, L.F., de la Fuente, J.L., Garcia, C. and Prieto, F.J. (1996). Hydropower generation management under uncertainty via scenario analysis and parallel computation. IEEE Trans. on Power Systems. Vol. 11, No.2, pp. 683-689.

Labadie, J. W. (2004). Optimal Operation of Multireservoir Systems: State-of-the-art Review. Journal of Water Resources Planning and Management, Vol. 130, No. 2, pp. 93-111.

Maceira, M.E.P., Terry, L.A., Costa, F.S., Damázio, J.M. and Melo, A.C.G. (2002). Chain of optimization models for setting the energy dispatch and spot price in the Brazilian system. Proceedings of the Power System Computation Conference - PSCC'02, Sevilla, Spain.

Martinez, L. and Soares, S. (2001) Comparison between Closed-Loop and Partial Open-Loop Feedback Control Policies in Long-term Hydro-thermal Scheduling. IEEE Trans. on Power Systems. Vol. 17, No. 2, pp. 330-336.

Oliveira G.G. and Soares S. (1995). A Second-Order Network Flow Algorithm for Hydro-thermal Scheduling", IEEE Trans. on Power Systems. Vol. 10, No. 3, pp. 1652-1641.

Pereira, M.V.F. and Pinto, L.M.V.G. (1985) Stochastic Optimization of Multireservoir Hydroelectric System: A Decomposition Approach. Water Resources Research, Vol.21, No.6, pp. 779-792.

Pereira, M.V.F. and Pinto, L.M.V.G. (1991). Multi-stage stochastic optimization applied to energy planning. Mathematical Programming, 52(2), 359-375.
Philbrick, C. R. and Kitanidis, P.K. (1999). Limitations of Deterministic Optimization Applied to Reservoir Operations. Jour. of Water Res. Planning Management, Vol. 125, No. 3, pp. 135-142.

Rosenthal, R.E. (1981) A nonlinear network flow algorithm for maximization of benefits in a hydroelectric power system. Operations Research. Vol. 29, No. 4, pp. 763-785.

Stedinger, J.R., Sule, B. F. and Loucks,D. P. (1984). Stochastic Dynamic Programming Models for Reservoir Operation Optimization. Water Resources Research, Vol. 20, No. 11, pp. 1499-1505.

Tse, E. and Bar Shalom, Y. (1975). Generalized certainty equivalence and dual effect in stochastic control. IEEE Transactions on Optimal Control. AC. 20, pp. 817-819.

Turgeon, A. (1980). Optimal operation of multireservoir systems with stochastic inflows. Water Resources Research. Vol. 16, No 2, pp.275-283.

Valdes, J.B., Filippo, J.M.D., Strzepek, K.M. and Restrepo, P.J. (1995). Aggregation-disaggregation approach to multireservoir operation. ASCE Journal of Water Resource Planning Management. Vol. 121, No. 5, pp. 345-351.

Zambelli, M., Luna, I. and Soares, S (2009). LongTerm Hydropower Scheduling Based on Deterministic Nonlinear Optimization and Annual Inflow Forecasting Models. In: 2009 IEEE Bucarest Power Tech, Bucarest, Romania.

Zambelli, M. S., Siqueira, T. G., Cicogna, M. A. and Soares, S. (2006). Deterministic Versus Stochastic Models for Long-term Hydro-thermal Scheduling, Procedings of Power Engineering Society General Meeting - PESGM' 2006, Montreal, Canada.

Zambelli, M., Toscano, A. E., Soares, S., Santos, E. F. and Nogueira, L. (2010). Newave Versus Odin Comparação Entre Modelo Estocástico e Determinístico No Planejamento da Operação Energética do Sistema Interligado Nacional. XVIII Congresso Brasileiro de Automática, Bonito-MS, pp. 347-354.

Zambelli, M.S. (2009). Planejamento da Operação Energética do Sistema Interligado Nacional Baseado em Modelo de Controle Preditivo, Tese de doutorado, FEEC/UNICAMP, Campinas. 